\title{
SISTEMA AUTOMATIZADO PARA AQUISIÇÃO DE DADOS DE UMIDADE RELATIVA DO Ả $\mathbf{R}^{1}$
}

\author{
KÉSIA O. DA SILVA², SERGIO O. MORAES ${ }^{2}$, JARBAS H. MIRANDA ${ }^{3}$, \\ ANDERSON M. PALMIERI ${ }^{4}$
}

\begin{abstract}
RESUMO: Devido à importância do ambiente na produção animal e vegetal e, portanto, controle ambiental adequado, o trabalho propõe como objetivo a construção de um sistema de aquisição automatizada de dados de umidade relativa do ar, utilizando-se de microcontrolador de dimensões reduzidas e de baixo custo. A calibração do sensor de umidade relativa foi realizada em três etapas de simulação desenvolvidas em laboratório: caixas perfuradas, dessecador sem tampa contendo sílica-gel em seu fundo e psicrometria. As etapas de calibração, utilizando situações naturais e artificiais, bem como as metodologias desenvolvidas, apresentaram resultados que permitem concluir que o sistema pode ser utilizado com segurança no monitoramento dessa variável.
\end{abstract}

PALAVRAS-CHAVE: variáveis climáticas, monitoramento do ambiente, instrumentação.

\section{AUTOMATED SYSTEM FOR RELATIVE HUMIDITY DATA ACQUISITION}

\begin{abstract}
Due the importance of the environment in animal and crop production and therefore an appropriate environmental control, the main objective of this work is the construction of an automated system for relative humidity data acquisition, using a controller with reduced dimensions and low cost. Calibration was performed under natural and artificial conditions. The methodology showed results that the system can be used for monitoring this environmental factor.
\end{abstract}

KEYWORDS: climatic variables, environment monitoring, instrumentation.

\section{INTRODUÇÃO}

A atmosfera possui propriedades e condições físicas, como temperatura, umidade, pressão, direção e velocidade de deslocamento do ar, grau de nebulosidade e quantidade de precipitação.

O conceito de ambiente é amplo, uma vez que inclui todas as condições que influenciam no desenvolvimento dos animais (ROLLER \& STOMBAUGH, 1976). O ar atmosférico é um importante componente do ambiente, sendo a temperatura e a umidade relativa do ar os principais elementos psicrométricos responsáveis por dois processos importantes no desenvolvimento da produção: o aquecimento e o resfriamento. Em países de regime tropical, como o Brasil, o aquecimento torna-se o principal problema para obter alto rendimento, e em países de clima temperado, o resfriamento é um componente indesejável para o processo produtivo, pois, para cada fase da produção, são exigidas diferentes faixas de temperatura e umidade relativa. Essas medidas são de grande importância em áreas como agricultura, zootecnia e engenharia, e os fabricantes de instrumentos têm-se preocupado em oferecer grande variedade de equipamentos com aplicação nesses setores (NOBLE \& LE DIVICH, 1982; LE DIVICH \& REINALDO, 1989).

Todas essas propriedades mutáveis devem ser medidas com precisão toda vez que se deseje determinar o que ocorre no ar e como ele varia, caracterizando, assim, o tempo num dado momento e lugar. A exatidão das medidas vai depender, em grande parte, da precisão do instrumental utilizado (SILVA, 2000).

\footnotetext{
${ }^{1}$ Extraído da Dissertação de Mestrado do primeiro autor.

${ }^{2}$ Profa. Dra., Departamento de Engenharia Rural, ESALQ/USP, Av. Pádua Dias, 11, Piracicaba - SP, kosilva@esalq.usp.br

${ }^{3}$ Prof. Dr., Departamento de Ciências Exatas, ESALQ/USP, Piracicaba - SP.

${ }^{4}$ Aluno de Graduação em Ciência da Computação, Escola de Engenharia de Piracicaba - EEP, Piracicaba - SP.

Recebido pelo Conselho Editorial em: 28-2-2007

Aprovado pelo Conselho Editorial em: 24-9-2007
} 
A umidade relativa do ar é medida normalmente por psicrômetros, higrômetros e registrada por higrógrafos, embora, atualmente, existam sensores eletroeletrônicos que também permitem o monitoramento da umidade instantânea ou contínua, quando operados com sistemas de aquisição de dados (SILVA, 2000).

Os sistemas de automação permitem monitorar e controlar o funcionamento de um sistema físico de forma segura, rápida e automática. O controle visa a monitorar tarefas rotineiras e respostas comuns a certas características do ambiente (em que, ambiente significa tudo o que existe em torno do sistema de controle, inclusive animais). Existem inúmeros exemplos de sistemas de automação de aquisição de dados, com os mais variados graus de complexidade. Todos eles, entretanto, têm alguns pontos comuns que os caracterizam.

A automação na obtenção dos dados tem gerado avanços enormes no controle de ambientes, pois permite rapidez e confiabilidade na aquisição dos dados, contribuindo para a tomada rápida de decisões (DALLY et al.,1993).

A maioria dos sistemas de automação necessita de algum tipo de parâmetro que lhes permita avaliar o estado atual do ambiente. Essa interface, geralmente, consiste de sensores que medem características do local, tais como temperatura, umidade relativa, intensidade luminosa e outros. Dependendo do tipo de sensor, o sistema terá maior ou menor precisão.

Uma alternativa para evitar erros de leitura desse tipo é a utilização de sensores digitais, mais modernos. O sistema digital oferece muitas vantagens em relação ao sistema analógico, pois um sinal digital é menos sensível às interferências eletromagnéticas e, além disso, o protocolo de comunicação estabelece mecanismo que permite detectar e corrigir erros de transmissão (SILVA, 2000).

O "Basic Stamp" é um microcontrolador de dimensões reduzidas e de baixo custo, facilmente programável em "BASIC", podendo ser utilizado em qualquer microcomputador. O seu nome deve-se ao fato de que o mesmo é do tamanho de um selo postal ("stamp" em inglês) (BERNARDES, 1996). Esse sistema pode ser aplicado para resolver vasta gama de problemas de controle, sem a necessidade de usar circuitos dedicados e complexos, como, por exemplo, na indústria, em automação de processos, máquinas e equipamentos, linhas de montagem, linhas de teste, banhos químicos, controle de nível de líquidos, controle de temperatura. No comércio, como miniterminal para automação de controle de estoque, pedidos e vendas. Na segurança, no controle de acesso, alarmes, simulações aleatórias de presença, controle de portão automático. Na educação, no ensino de programação, eletrônica digital, robótica e automação de processo, trabalhos e projetos disciplinares. No setor automotivo, na confecção de alarme, bloqueador, contagiros, medidor de consumo. Em casa, no controle de eletrodomésticos, iluminação, nível de caixa d'água, e no modelismo, como controle de mecanismos para aeromodelos, automação de ferromodelismo e automação de maquetes (SILVA, 2000).

JACKSON (1998) construiu uma estação meteorológica automatizada utilizando os recursos do sistema de aquisição de dados do "Basic Stamp", no qual se armazenam os dados de temperatura e umidade relativa do ar, velocidade do vento, pressão atmosférica, precipitação, etc.

Existem no mercado vários outros tipos de sistemas de aquisição de dados com a mesma finalidade de obter e armazenar dados meteorológicos, sendo o preço e a qualidade do produto as características básicas para sua escolha.

A análise de custos de um projeto passa a ser um dos critérios de decisão para a sua implantação. Portanto, para atender às necessidades do mercado, o produtor tem de adequar sua produção cada vez mais às exigências do consumidor, procurando sempre obter um produto de qualidade e ofertá-lo com maior rapidez.

Tendo em vista as necessidades do setor produtivo em disponibilizar no mercado produtos e serviços competitivos, ou seja, produtos com qualidade a baixos custos, o controle ambiental assume posição de destaque. Diante da importância desses fatores, o presente trabalho apresenta 
como objetivos, a construção e a calibração de um sistema de aquisição de dados facilmente programável pela porta paralela de um microcomputador, utilizando linguagem de programação PBASIC, que é muito próxima ao BASIC tradicional, utilizando-se, para tal, de um microcontrolador de dimensões reduzidas e de baixo custo ("Basic Stamp"), neste caso, buscando compará-lo com outros sistemas já existentes.

\section{MATERIAL E MÉTODOS}

O trabalho foi conduzido junto ao Departamento de Ciências Exatas, da Escola Superior de Agricultura "Luiz de Queiroz", ESALQ/USP, Piracicaba - SP, compreendendo as etapas de montagem do sistema e calibração. Na montagem do sistema, utilizou-se do BASIC STAMPII (BSII, PARALLAX Inc. (R)) como microcontrolador para a aquisição dos dados de umidade relativa do ar.

O esquema de pinos do "BASIC Stamp I", que é mais simples, está representado pela Figura 1.

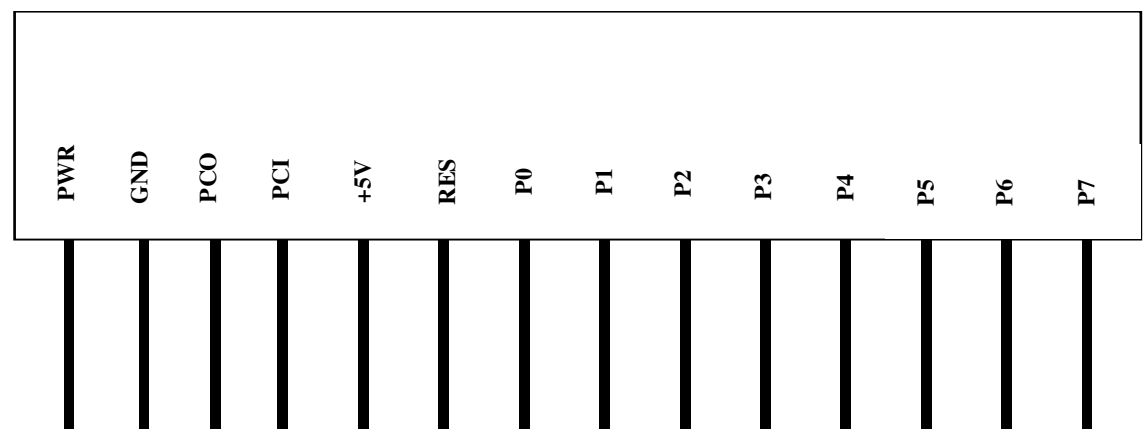

FIGURA 1. Representação do esquema de pinos do "BASIC Stamp"

em que,

PWR - entrada de força não-regulada. Aceita 6 - 15 VDC, que é então regulada para 5 Volts. Não pode ser conectado se for aplicada uma fonte de 5 Volts ao pino $+5 \mathrm{~V}$;

GND - "Ground" (terra) do sistema. Conectado ao pino 25 (GND) da porta paralela do PC para programação;

PCO - PC Out. Conectado ao pino 11 (Busy) da porta paralela do PC para programação;

PCI - PC In. Conectado ao pino 2 (DO) da porta paralela do PC para programação;

$+5 \mathrm{~V}$ - entrada/saída de 5 Volts. Se uma tensão desregulada é aplicada ao pino PWR, então esse pino proverá uma tensão de 5 Volts. Se nenhuma tensão for aplicada ao pino PWR, então uma tensão regulada entre $4,5 \mathrm{~V}$ e $5,5 \mathrm{~V}$ deverá ser aplicada nesse pino $(+5 \mathrm{~V})$

RES - entrada/saída de RESET. Vai no nível lógico baixo (zero) quando a tensão de alimentação for menor que 4 Volts, fazendo o BSII ficar na condição de RESET. Pode ser forçado para a condição de nível lógico baixo (zero) para forçar um RESET;

PO-P7 - pinos de I/O de uso genérico. Cada pino pode fornecer uma corrente de $265 \mathrm{~mA}$ em pico e $20 \mathrm{~mA}$ contínuo. Porém, a soma de corrente de todos os pinos não pode exceder $50 \mathrm{~mA}$ de pico e $40 \mathrm{~mA}$ contínuo.

O "BASIC Stamp II" possui 16 "bytes" de RAM dedicados para I/O e armazenamento de variáveis. Os dois primeiros "bytes" são usados para I/O (um para dados e o outro para controle de direção), os outros 14 "bytes" são para dados. A linguagem BASIC do "BASIC Stamp R" é muito flexível em nomear variáveis e pinos de I/O.

O sistema pode ser alimentado por uma bateria de 9 Volts ou por eliminador de baterias ligado na rede de energia elétrica e esse conectado ao "Basic Stamp II". O sensor de umidade relativa utilizado foi da Philips Components (código 2322691 90001), formado por uma folha de material não-condutivo coberta nas duas faces por uma finíssima camada de ouro (metal condutor), de forma que essa estrutura corresponde, justamente, a um capacitor plano. 
O conjunto foi montado num invólucro dotado de pequenos orifícios para acesso do vapor d'água ao dielétrico. O sensor abrange faixa de umidade de $10 \%$ a $90 \%$; capacitância a $25{ }^{\circ} \mathrm{C}$ com $43 \%$ de umidade relativa, numa frequiência de $100 \mathrm{kHz}$ : $122 \mathrm{pF}(+/-15 \%)$; sensibilidade entre 12 e $75 \%$ de umidade relativa: $0,4 \mathrm{pF} / \%$; faixa de freqüências de operação: $1 \mathrm{kHz}$ a $1 \mathrm{MHz}$; tensão máxima $\mathrm{AC}$ ou DC: $15 \mathrm{~V}$; faixa de umidade para armazenamento: 0 a $100 \%$, e temperatura de operação: 0 a $85^{\circ} \mathrm{C}$ (BRAGA,1996).

Os diagramas esquemáticos dos sensores de umidade, juntamente com as respectivas dimensões, podem ser observados, respectivamente, nas Figuras 2A e 2B, na sua forma real, já conectados ao cabo coaxial.

Para a montagem eletrônica do "Basic Stamp II", sensores de umidade relativa do ar foram utilizados nos itens listados na Tabela 1.
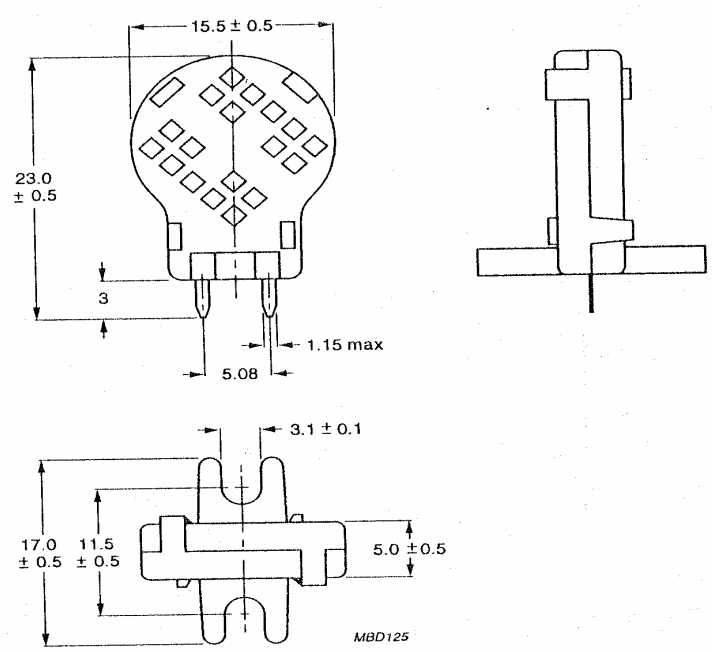

(a)

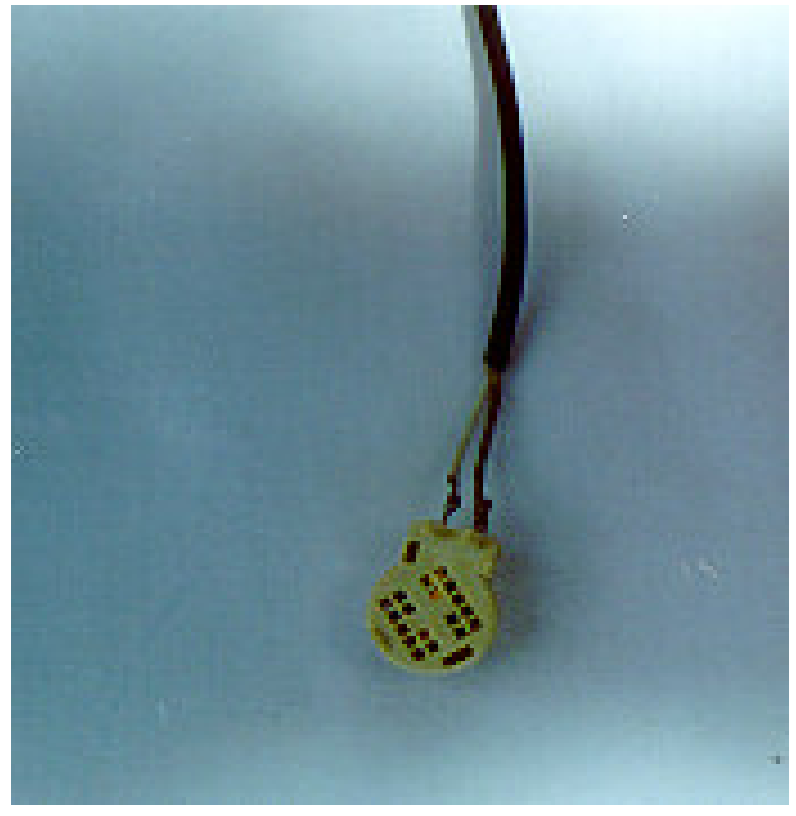

(b)

FIGURA 2. Diagrama esquemático do sensor de umidade relativa (a) e sensor de umidade relativa já conectado ao cabo coaxial (b).

TABELA 1. Lista de materiais utilizados na montagem eletrônica do "Basic Stamp II".

\begin{tabular}{ll}
\hline Material & Referência \\
\hline "Basic Stamp ${ }^{R, "}$ & BS2- 1C ou BSII \\
Sensor de umidade relativa - Philips (capacitivo) & 232269190001 \\
2 capacitores & $33 \mathrm{pF}-(\mathrm{C} 1, \mathrm{C} 2)$ \\
1 capacitor & $1 \mathrm{nF}-(\mathrm{C} 3)$ \\
1 capacitor & $10 \mathrm{nF}-(\mathrm{C} 4)$ \\
1 capacitor & $2.2 \mathrm{uF}-(\mathrm{C} 5)$ \\
1 resistor & $10 \mathrm{M}-(\mathrm{R} 1)$ \\
1 resistor & $10 \mathrm{~K}-(\mathrm{R} 2)$ \\
1 resistor & $1 \mathrm{M}-(\mathrm{R} 3)$ \\
1 resistor & $100 \mathrm{~K}-(\mathrm{R} 4)$ \\
\hline Circuitos Integrados & \\
\hline 1 circuito integrado & $\mathrm{CL}-14060$ \\
1 circuito integrado & $555 \mathrm{AST}$ \\
Conversor & analógico/digital \\
Bateria & 9 volts \\
\hline
\end{tabular}




\section{Calibração do sensor de umidade relativa}

A calibração do sensor de umidade relativa, da Philips Components, foi realizada em três etapas de simulação desenvolvidas em laboratório, conforme os ambientes artificiais foram sendo criados.

Na primeira, utilizaram-se duas caixas plásticas perfuradas e posicionadas uma em frente à outra, e um psicrômetro não-ventilado, considerado como padrão, colocado em seu interior, juntamente com o sensor a ser calibrado, presos um ao outro por uma fita plástica. Em seguida, cobriram-se as caixas por um tecido embebido em água destilada, simulando-se, assim, um ambiente saturado (Figuras 3a, 3b e 3c).

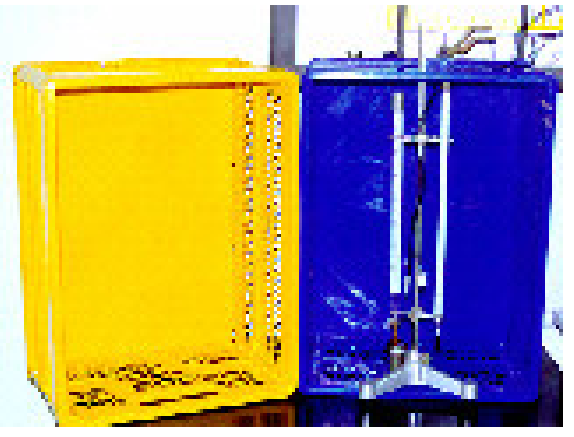

(a)

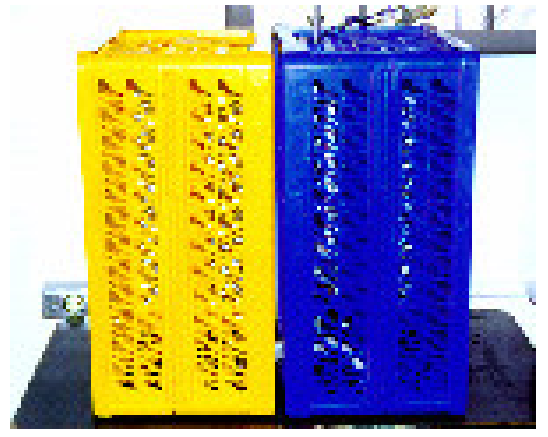

(b)

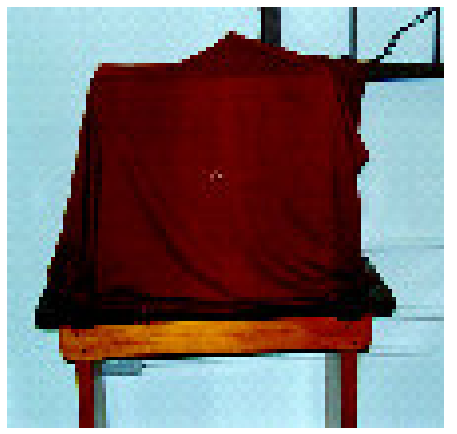

(c)

FIGURA 3. Disposição dos instrumentos dentro da caixa plástica (a), caixas plásticas perfuradas já fechadas (b) e tecido embebido em água destilada cobrindo as caixas plásticas perfuradas (c).

Após aguardar cerca de 40 minutos, deu-se início às leituras dos pares de dados, que eram relativas às leituras de temperatura do bulbo seco e bulbo úmido e, ao mesmo tempo, do sinal do sensor de umidade relativa. As medidas foram feitas a cada hora, durante 7 horas, mantendo-se sempre o tecido umedecido com água destilada, para assegurar que o ambiente se encontrava constantemente saturado e, portanto, em qualquer momento os sensores estavam em equilíbrio com o ambiente. De hora em hora, abriam-se as caixas e liam-se os instrumentos, fechando-se o sistema novamente.

Na segunda etapa, utilizou-se de um dessecador sem tampa, contendo sílica-gel em seu fundo. $\mathrm{O}$ sensor de umidade a ser calibrado e o psicrômetro não-ventilado foram dispostos no interior do dessecador sobre uma grade de louça, situada acima da sílica-gel. O dessecador contendo o psicrômetro e o sensor foram cobertos por um plástico transparente de modo a isolá-los do ambiente externo, isto é, o saco plástico fixado por fita adesiva atuava como tampa do dessecador e permitia a leitura dos instrumentos sem sua remoção. Para dar início às leituras, aguardou-se uma hora.

Após esse período, iniciaram-se as leituras de hora em hora até obter a estabilidade do ambiente. $\mathrm{O}$ ambiente estabilizou-se no menor valor de umidade relativa conseguido pela sílicagel.

Para melhorar a curva de calibração, foram gerados mais três pontos intermediários e, para tal, utilizou-se de três tipos de sais: cloreto de sódio, dicromato diidratado de sódio e o cloreto hexaidratado de magnésio (Tabela 2), de modo a condicionar a cada sal uma respectiva umidade, quando mantido em ambiente fechado e saturado, em dada temperatura.

Para a calibração do sensor de umidade, utilizou-se de um pequeno vidro transparente cuja tampa serviu de suporte para o sensor de umidade relativa a ser calibrado e para o termômetro de mercúrio. Seguiu-se, então, a metodologia proposta por YOUNG (1967), que se baseia em colocar uma determinada quantidade de água destilada no interior de um frasco e, em seguida, o sal, de 
maneira a saturar a solução. Essas umidades-padrão e os sinais elétricos gerados pelo sensor de umidade permitiram sua calibração e, portanto, completou-se a programação do BS II.

TABELA 2. Sais utilizados na calibração do sensor de umidade relativa com suas respectivas temperaturas e umidades relativas.

\begin{tabular}{lcc}
\hline Tipos de Sais Utilizados & Temperatura $\left({ }^{\circ} \mathrm{C}\right)$ & UR $(\%)$ \\
\hline Cloreto de sódio & 25 & 75,1 \\
Dicromato diidratado de sódio & 15 & 53,7 \\
Cloreto hexaidratado de magnésio & 15 & 32,7 \\
\hline
\end{tabular}

\section{RESULTADOS E DISCUSSÃO}

\section{Custo do equipamento}

Um dos fornecedores que comercializa esse equipamento no Brasil, é a Anacom (www.anacom.com.br), sendo o preço total, em dólares, do sensor de umidade relativa, juntamente com o de temperatura, de US\$29,95, e o sistema de aquisição de dados de US\$ 49,00. Em termos comparativos com outros sistemas já existentes no mercado, podemos citar o registrador de dados de umidade relativa do ar e temperatura, da marca HOBO (modelo H8032 com quatro canais, sendo dois canais para temperatura e umidade relativa do ar e mais dois canais externos), possui preço em torno de $\mathrm{R} \$ 880,00$, ou seja, custo bem superior ao apresentado anteriormente que, após a conversão, apresenta custo em torno de R \$ 165,00 (conversão 1 US\$ = R \$ 2,09, em 11-7-2007).

\section{Resultado da primeira tentativa para a calibração do sensor de umidade relativa}

Os resultados obtidos no ambiente natural interno do laboratório mostraram fraca correlação, com $\mathrm{R}^{2}$ igual a 0,4672 (Figura 4), obtida com os dados do psicrômetro ventilado e o sinal elétrico do sensor capacitivo. Esse fato pode estar associado a duas causas simultâneas: os diferentes tempos de resposta dos instrumentos, fazendo com que cada um fornecesse valores de umidade distintos, por não estarem simultaneamente em equilíbrio, e a interferência devido à aproximação do operador e sua permanência junto aos instrumentos por alguns minutos, para acionar o mecanismo de ventilação e efetuar as leituras das temperaturas de bulbo seco e bulbo úmido.

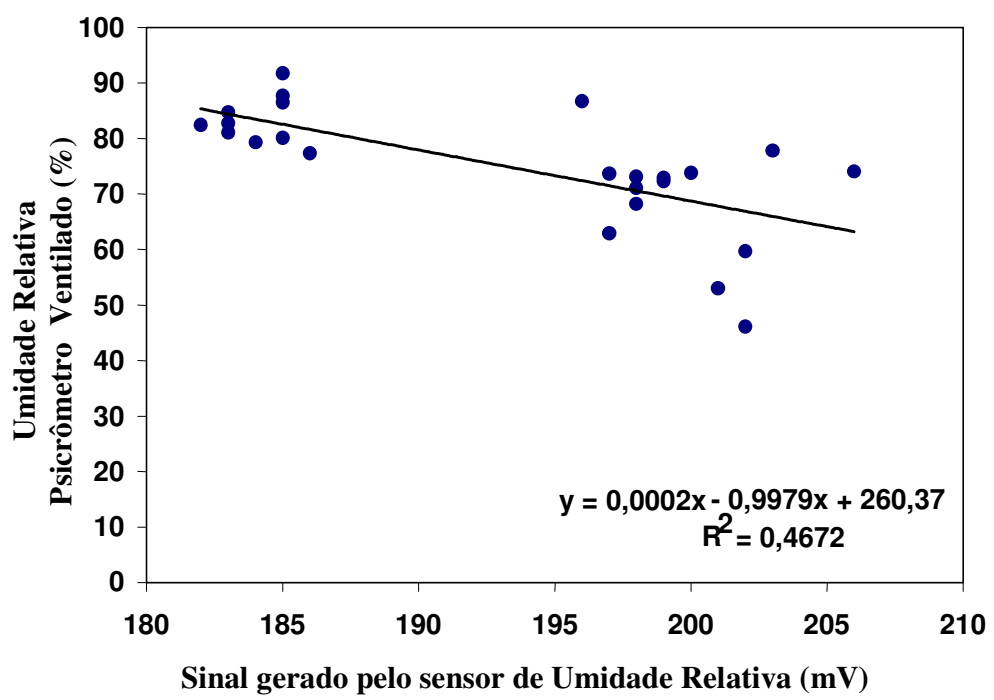

FIGURA 4. Correlação entre os dados da umidade relativa obtida com os dados do psicrômetro ventilado e o sinal gerado pelo sensor de umidade relativa no interior do laboratório.

O operador pode também ter interferido na umidade relativa do ambiente, causando com mais intensidade as diferenças de medidas entre o sensor a ser calibrado e o psicrômetro ventilado, pelo fato de o sensor possuir tempo de resposta menor, comparado ao psicrômetro ventilado. 
No entanto, a segunda regressão, que utilizou o termoigrógrafo, apresentou forte correlação $\left(\mathrm{R}^{2}=0,8268\right)$ devido ao fato de esse instrumento registrar a umidade do ar continuamente, talvez não sendo tão afetado por interferências na umidade ambiente (Figura 5).

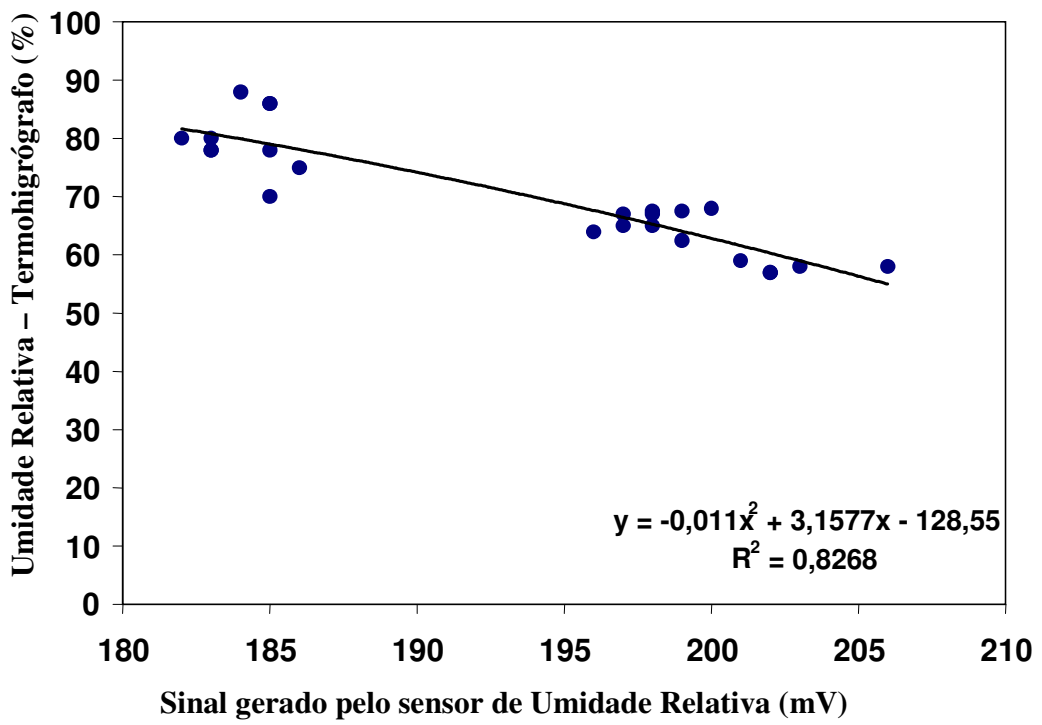

FIGURA 5. Correlação entre os dados da umidade relativa fornecida pelo termoigrógrafo e o sinal gerado pelo sensor de umidade relativa no interior do laboratório.

\section{Resultado da segunda tentativa para a calibração do sensor de umidade relativa}

Observou-se que os resultados das correlações de cada instrumento com o sinal elétrico do sensor não indicam correlações fortes. De acordo com BRAGA (1996), o sensor necessita de, pelo menos, 10 minutos para entrar em equilíbrio com a umidade relativa em dado ambiente. Para isso, seria necessário um lugar onde a umidade se mantivesse constante por, no mínimo, 10 minutos, para então obter, com certeza, o valor correto.

Como nessa segunda tentativa de calibração, o sensor e os equipamentos estavam dispostos num local onde a umidade variava muito, numa faixa de 40 a $90 \%$, não foi possível obter boas correlações, pois os diferentes tempos de resposta de cada instrumento-padrão não permitiram acompanhar as variações rápidas do vapor d'água em um mesmo instante. De acordo com PEARCY et al. (1989), quando a faixa de vapor d'água na atmosfera variar de 0 a $75 \%$, o tempo de resposta desse tipo de sensor é muito curto, em torno de milésimos de segundos, e se torna mais lento com a redução da umidade relativa.

\section{Resultado da terceira tentativa para a calibração do sensor de umidade relativa}

A fraca correlação entre os dados dos instrumentos (psicrômetro ventilado, psicrômetro nãoventilado e termoigrógrafo) utilizados para medir a umidade relativa do ar com os resultados do sensor capacitivo foi em função da rápida variação da umidade ambiental, o que indica atraso nos dados emitidos pelos equipamentos, ao passo que o sensor os fornecia instantaneamente. Essa foi a principal causa de diferença entre os valores obtidos pelos três instrumentos e o sensor, pois cada um determinava a umidade de acordo com seu tempo de resposta.

Sabendo-se que o psicrômetro pode ser utilizado como instrumento de referência para a medição da umidade do ar e que a precisão dos valores de vapor d'água obtidos pelo mesmo vai depender da precisão dos termômetros utilizados, PEARCY et al. (1989) observaram que o psicrômetro não-ventilado, citado na segunda tentativa de calibração, possui ótima precisão de 0,2\%; por esse motivo, foi escolhido como padrão único para participar da terceira etapa de calibração. Devido os termômetros de bulbo seco e bulbo úmido do psicrômetro ventilado apresentarem menor precisão de $0,5 \%$ e também ao fato da necessidade da proximidade do 
operador para o seu funcionamento, o que de certa forma influenciaria na umidade do ambiente, não foram escolhidos.

Para obter ambiente com a umidade constante e conjunto suficiente de valores para fornecer a curva de calibração, foram simulados microclimas (Tabela 3 ).

Com a simulação dos microclimas, obtiveram-se as umidades mais precisas devido à constância da umidade de cada ambiente. Foi obtida, portanto, uma equação de regressão para esse ensaio de calibração, que apresentou ótimo coeficiente de determinação (Figura 6), sendo incluída no programa de aquisição de dados.

TABELA 3. Tipos de ambientes utilizados, valores de umidade relativa e sinais gerados pelo sensor.

\begin{tabular}{lcc}
\hline Tipos de Ambientes Utilizados & Umidade Relativa (\%) & Sinais do Sensor \\
\hline Ambiente saturado & 100 & 203 \\
Cloreto de sódio & 72 & 194 \\
Ambiente utilizando sílica-gel & 60,18 & 192 \\
Ambiente utilizando sílica-gel & 57,83 & 191 \\
Dicromato diidratado de sódio & 53,7 & 189 \\
Cloreto hexaidratado de magnésio & 32,7 & 184 \\
\hline
\end{tabular}

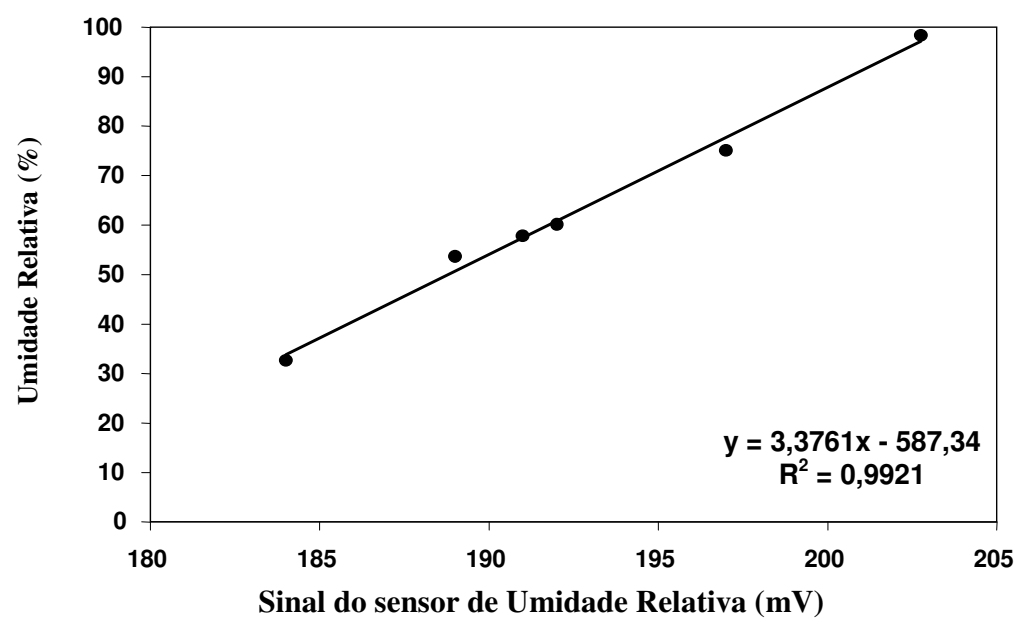

FIGURA 6. Curva de regressão relacionando os dados de umidade relativa (\%) e do psicrômetropadrão, e respectivas leituras do BSII $(\mathrm{mV})$.

\section{CONCLUSÕES}

Em termos de calibração, cabe ressaltar que houve desempenho superior em ambiente controlado, comparado com as medições de um psicrômetro não-ventilado. A utilização do "BASIC STAMP (R)" na confecção de um sistema de aquisição de dados de temperatura e umidade relativa mostrou-se totalmente viável, tanto pela facilidade de operação quanto pelo custo do sistema, comparado com outro sistema já comercialmente existente.

\section{REFERÊNCIAS}

BERNARDES, L.H.C. Basic stamp. Saber Eletrônica, São Paulo, v.32, n.1, p.16-24, 1996.

BRAGA, N.C. Medidor de umidade relativa. Saber Eletrônica, São Paulo, v.32, n.1, p.41-4, 1996.

DALLY, J.W.; WILLIAM, F.R.; McCONNELL, K.G. Instrumentation for engineering measurements. $2^{\text {nd }}$ ed. New York: John Wiley, 1993. 584 p. 
JACKSON, R.M. The weather stamp meteorological station. Disponível em: http://www.tparnell@oeonline.com. Acesso em: 25 nov. 1998.

LE DIVICH, J.; REINALDO, D. Effes de I'environnement thermique sur les performance du porc en croissance. Journées Rech. Porcine en France, Paris, v.21, p.221-9, 1989.

NOBLE, J.; LE DIVICH. Effect of environmental temperature and feeding level on energy balance traits of early-weand pigles. Livest Production Sciences, Amsterdam, v.9, 619-32, 1982.

PEARCY, R.W. Plant physiological ecology: field methods and instrumentation. London: British Library, 1989. 442 p.

ROLLER, W.L.; STOMBAUGH, D.P. The influence of environmental factors on the reproduction of livestock. In: INTERNATIONAL SYMPOSIUM LIVESTOCK ENVIRONMENT, 1976, Atlanta. Proceedings... Atlanta: ASAE, 1976. v.1, p.31-50.

SILVA, K.O. Desenvolvimento de sistema automatizado de baixo custo para aquisição de dados de umidade e temperatura do ar. 2000. 70 f. Dissertação (Mestrado em Física do Ambiente Agrícola) - Escola Superior de Agricultura "Luiz de Queiroz”, Universidade de São Paulo, Piracicaba, 2000.

YOUNG, J.F. Humidity and control in the laboratory using salt solutions. Journal of Applied Chemistry, London, v.17, p.170, Sep. 1967. 